\title{
Integrity of white matter structure is related to episodic memory performance in the low-educated elderly
}

\author{
Memória e integridade da substância branca em idosos de baixa escolaridade \\ Elisa de Paula França Resende1, Fernanda Freire Tovar-Moll², Fernanda Meireles Ferreira², Ivanei Bramati², \\ Leonardo Cruz de Souza', Karoline Carvalho Carmona1, Henrique Cerqueira Guimarães', Viviane Amaral \\ Carvalho', Maira Tonidandel Barbosa', Paulo Caramelli ${ }^{1}$
}

\begin{abstract}
The low-educated elderly are a vulnerable population in whom studying the role of white matter integrity on memory may provide insights for understanding how memory declines with aging and disease. Methods: Thirty-one participants (22 women), 23 cognitively healthy and eight with cognitive impairment-no dementia, aged $80.4 \pm 3.8$ years, with $2.2 \pm 1.9$ years of education, underwent an MRI scan with diffusion tensor imaging (DTI) acquisition. We verified if there were correlations between the performance on the Brief Cognitive Screening Battery (BCSB) and the Rey Auditory Verbal Learning Test (RAVLT) with DTI parameters. Results: The BCSB delayed recall task correlated with frontotemporoparietal connection bundles, with the hippocampal part of the cingulum bilaterally and with the right superior longitudinal fasciculus. The RAVLT learning and delayed recall scores also correlated with the hippocampal part of the cingulum bilaterally. Conclusions: Although preliminary, our study suggests that the integrity of white matter frontotemporoparietal fasciculi seems to play a role in episodic memory performance in the low-educated elderly. This finding opens opportunities to study potential targets for memory decline prevention in vulnerable populations.
\end{abstract}

Keywords: episodic memory; aging; white matter; health vulnerability.

\begin{abstract}
RESUMO
Idosos de baixo nível educacional representam uma população vulnerável em que o estudo do papel da integridade da substância branca na memória pode revelar como essa declina no envelhecimento. Métodos: Trinta e um indivíduos (22 mulheres), sendo 23 cognitivamente saudáveis, oito com comprometimento cognitivo não demência, 80,4 $\pm 3,8$ anos de idade e 2,2 \pm 1,9 anos de escolaridade, foram submetidos à RM com imagem de tensor de difusão, cujos parâmetros foram correlacionados com a Bateria Cognitiva Breve (BCSB) e o Teste Auditivo Verbal de Rey (RAVLT). Resultados: A evocação tardia da BCSB correlacionou-se com fascículos de conexão frontotemporoparietal, fascículo longitudinal superior direito e cíngulo parte hipocampal bilateral, sendo que esse último também correlacionou com o RAVLT (aprendizado e evocação tardia). Conclusão: Apesar de preliminar, nosso estudo sugere que a integridade da substância branca parece ser importante para a memória em idosos de baixa escolaridade, achado que revela alvo potencial na prevenção do seu declínio em populações vulneráveis.
\end{abstract}

Palavras-chave: memória episódica; envelhecimento; substância branca; vulnerabilidade em saúde.

Memory decline occurs in normal aging and is also a core feature of the most common cause of dementia, Alzheimer's disease $^{1}$. As the prevalence of this disorder and other forms of dementia is higher in developing countries ${ }^{2}$, it is important to explore the neural correlates of episodic memory in the setting of low education, a situation extremely common among the elderly population in low- and middle-income countries. Hence, understanding the anatomic substrate of memory performance, especially in vulnerable individuals, can help to develop strategies to prevent cognitive decline in this scenario.

Apart from the hippocampus and the medial temporal lobe structures, well-established episodic memory cortical correlates ${ }^{3}$, recent studies have demonstrated that white

\footnotetext{
'Universidade Federal de Minas Gerais, Faculdade de Medicina da Belo Horizonte, Departamento de Clínica Médica, Grupo de Pesquisa em Neurologia Cognitiva e do Comportamento, Belo Horizonte MG, Brasil;

2IDOR - Instituto D’Or de Pesquisa e Ensino, Rio de Janeiro RJ, Brasil.

Correspondence: Paulo Caramelli; Faculdade de Medicina da Universidade Federal de Minas Gerais; Av. Prof Alfredo Balena, 190 / sala 246; $30130-100$ Belo Horizonte MG, Brasil.; E-mail: caramelli@ufmg.br

Conflict of interest: There is no conflict of interest to declare.

Support: CNPq, Fundação de Apoio à Pesquisa de Minas Gerais and Instituto Hermes Pardini. Paulo Caramelli is funded by CNPq (bolsa de produtividade em pesquisa). Received 26 April 2017; Received in final form 02 August 2017; Accepted 11 August 2017.
} 
matter also plays a crucial role. Previous studies have shown that memory function was associated with white matter integrity in the inferior and superior longitudinal fasciculi, the posterior and anterior cingulum ${ }^{4}$ the uncinate fasciculus, the dorsal cingulum bundle ${ }^{5}$ and the hippocampal part of the cingulum 6 . However, these studies have explored the correlation between episodic memory and white matter integrity in highly-educated individuals, selected under strict criteria from research centers ${ }^{5,7}$. Hence, the role of white matter integrity on episodic memory in community-dwelling elderly with a low educational level remains to be explored.

Advanced neuroimaging techniques, such as diffusion tensor imaging (DTI) acquired through magnetic resonance imaging (MRI), have allowed the study of the integrity of white matter tracts with fair precision ${ }^{8}$. This method is based on the anisotropic property of water molecules, characterized by nonrandom movement when constricted by structures such as the neuron membrane and the myelin sheath. By acquiring a DTI image, it is possible to detect these movements and to establish the directionality using diagonalization to calculate the vectors. Thereafter, these vectors can be used to calculate measures that correlate with white matter integrity, such as the fraction anisotropy (FA) and the mean diffusivity (MD). The former reflects the longitudinal directionality of the water molecules' movement, and reduces with white matter microstructural integrity disruption ${ }^{9}$. Conversely, the latter measure reflects the radial directionality, which increases with white matter lesions. These two parameters can be correlated with cognitive performance, enabling us to make inferences about the role of the integrity of white matter on cognitive paradigms, such as episodic memory.

Although the relationship between white matter integrity and episodic memory has been explored in highly-educated individuals, in this study we used DTI to explore the role of white matter integrity on episodic memory performance in a low-educated elderly sample. A high magnetic field ${ }^{10}$ and an advanced post-processing approach - whole-brain tract-based spatial statistics - were used to generate a reliable interpretation of multiple DTI analyses ${ }^{11}$. We hypothesized that, in low-educated individuals, episodic memory performance would correlate with the white matter integrity of connection bundles between the medial temporal lobe and frontoparietal regions, similar to that which happens in highly-literate individuals.

\section{METHODS}

\section{Participants}

The participants were selected from the Pietà study, a community-based investigation on brain aging conducted in Caeté (Minas Gerais state), Brazil ${ }^{12}$. Six hundred thirty-nine individuals, corresponding to $51.1 \%$ of the city population aged 75+ years were evaluated. The Ethics Committee of the Federal University of Minas Gerais approved this study and all participants or their legally-authorized representatives provided written informed consent. The clinical, functional, neurological and psychiatric status of the participants were established and they were classified into three cognitive performance categories: cognitively healthy, cognitive impairment-no dementia, and dementia. For this study purpose, we included both cognitively healthy and cognitive impairmentno dementia individuals to improve the range of performance in the memory tests, allowing the detection of white matter micro structural changes. Because it was a population-based study, the cognitive impairment-no dementia concept was used instead of mild cognitive impairment. Individuals were considered cognitive impairment-no dementia when, regardless of cognitive complaints by the patient or the informant, objective cognitive impairment was detected in the cognitive assessment ${ }^{13}$. Demented individuals were excluded from this study because our primary aim was to analyze the influence of white matter integrity on cognitive performance in individuals with preserved functional status.

\section{Cognitive assessment}

Participants were evaluated using the Mini-Mental State Evaluation (MMSE) ${ }^{14}$ and two episodic memory tests, namely the memory test from the Brief Cognitive Screening Battery (BCSB) ${ }^{15}$ and the Rey Auditory Verbal Learning Test $(\text { RAVLT })^{16}$. The BCSB memory test evaluates both visual and verbal memory. It consists of the presentation of 10 simple drawings that are first identified and named. Immediately after, the participant is asked to recall the drawings (incidental encoding). The sheet of paper is then shown again for 30 seconds, the patient is asked to memorize the figures, and recall is requested immediately after. The latter procedure is performed twice, leading to a score for immediate memory and learning. After that, interference activities are performed, namely, the category fluency test (animals/minute) and the clock drawing test. Then, the participant is asked to recall as many items as possible in a delayed recall task. Finally, the participant is confronted with the 10 previously-presented drawings along with 10 distractors, and is asked to recognize the initial drawings. On the other hand, the RAVLT essentially assesses verbal memory. It consists of 15 words read aloud for five consecutive trials (List A), followed by a free-recall test (A1 through A5). After the fifth trial, a new interference list of 15 words is presented (List B) followed by a free-recall test of that list (B1). After that, a free-recall of List A is requested (A6). After a 30-minute delay period filled with distractor activities, the participant is again asked to recall words from List A (A7). Finally, the patient is required to identify List A words from a list of 50 words, which includes Lists A, List B and 20 other words phonemically or semantically related to those of Lists A and B (recognition item). 
Neuroimaging data acquisition and processing

A random subsample of individuals from the Pietà study $(\mathrm{n}=200)$ was asked to take part in the MRI examination. The effective sample used in this study $(n=49)$ included participants with an acceptable quality of the DTI images acquired in a 3 Tesla Philips Achieva scanner. The diffusion-weighted images were obtained in the axial plane with a singleshot, spin-echo, echo planar sequences in the axial plane $(\mathrm{TR} / \mathrm{TE}=8000 / 65 \mathrm{~ms}, \mathrm{FOV}=240 \mathrm{~mm}$, matrix $=96 \times 96$ (reconstructed 128x128), slice thickness $=2.0 \mathrm{~mm}$ with 1.99 $\mathrm{mm}$ gap between slices). Diffusion sensitization gradients were applied in 32 non-collinear directions, with a b factor of $1000 \mathrm{sec} / \mathrm{mm}^{2}$. Cognitive testing was completed within nine months of the MRI scans. An experienced radiologist, blind to the clinical diagnoses, calculated the Fazekas score ${ }^{17}$, a semi-quantitative visual scale for white matter lesions, which ranges from $0-6$, with 0 being no lesions and 6 severe and diffuse lesions, which was used to assess the participants' white matter lesions burden.

\section{Diffusion tensor imaging post-processing}

All diffusion images were inspected for artifacts. Non-diffusion and diffusion images were co-registered to correct for movement artifacts and eddy current distortion effects on the Echo Planar Imaging readout ${ }^{18}$. The diffusion tensor for each voxel was calculated using multivariate fitting and diagonalization (FSL 4.0 FMRIB software) ${ }^{19}$. Fractional anisotropy and MD images were brain-extracted and registered to the Montreal Neurological Institute space standard (MNI152) using constrained nonlinear registration (Image Registration Toolkit) ${ }^{20}$. The derived FA and MD data were further analyzed using a priori regions of interest (ROI) analyses and voxelwise whole-brain tract-based spatial statistics ${ }^{11}$.

\section{Whole-brain voxelwise analysis}

Whole-brain voxelwise statistical analyses of FA and MD were conducted to assess global correlations between those values and memory (BCSB delayed recall task, RAVLT learning and 30 minutes delayed recall using tract-based spatial statistics (FMRIB Software Library, FSL) ${ }^{21}$, controlling for age and education. The results were considered significant at $\mathrm{p}<0.05$, using cluster-based Threshold-Free Cluster Enhancement fully corrected for multiple comparisons Family Wise Error Rate (FWE). The threshold-skeletonized resulting image was thickened for better visualization.

\section{Regions of interest analysis}

A Johns Hopkins University DTI-MRI atlas of human white matter ${ }^{22}$ was used to determinate fiber tract orientation, and the ROIs, and was considered the reference for anatomical labels, which were checked by an experienced investigator (FMF) afterward. The ROIs for memory correlation were placed along the hippocampal part of the cingulum, which runs along the surface of the corpus callosum and hippocampal parts, the superior longitudinal fasciculus, which connects the frontal, temporal, parietal and occipital lobes, and the uncinate fasciculus, which connects medial prefrontal and anterior temporal brain regions. These fasciculi were selected because they are either part of the limbic system (hippocampal part of the cingulum and uncinate), which is classically associated with memory, or because they are important for attention and working visuospatial memory (superior longitudinal fasciculus) ${ }^{23}$. Multiple regression analyses including age and education as covariates were carried out to investigate associations between the FA and MD values and memory performance tested by the RAVLT A1-A5 sum of scores, RAVLT A7 scores and BCSB delayed recall task score.

\section{Statistical analyses of demographic and clinical variables}

Statistical analyses were performed using the SPSS 16.0. Kolmogorov-Smirnov tests to assess parametric distribution. Group differences for demographic and clinical variables with parametric distribution were undertaken with the Student's t-test for age, RAVLT A1-A5 sum of scores, RAVLT A7 scores and the BCSB memory test delayed recall task score. The Mann-Whitney test was used for non-parametric distribution variables: years of education, MMSE and Fazekas scores. Associations between categorical variables were investigated with Chi-square and exact Fisher's test. The level of significance $(\alpha)$ was set at 0.05 , two-tailed, for all statistical tests.

\section{RESULTS}

\section{Demographical and clinical results}

Images were available for whole analyses for 31 participants (after excluding artifacts), of whom $22(70 \%)$ were women, with a mean age of $80.4 \pm 3.8$ years and $2.2 \pm 1.9$ years of education. Eight $(25 \%)$ participants were classified as cognitive impairment-no dementia. The whole group's mean score on the MMSE was $22.3 \pm 4.3$. The mean performance on the delayed recall task from the BCSB memory test was $7.1 \pm 1.7$ (maximum score $=10)$. The learning composite from the RAVLT (A1-A5) mean score was $23.7 \pm 8.8$ (maximum score $=75$ ) and the delayed recall task (A7) mean score was $4.3 \pm 3.5$ (maximum score $=15$ ). Global white matter injury accessed through the Fazekas scale was moderate, with a mean score of $2.7 \pm 1.6$.

\section{Voxelwise whole-brain DTI findings}

A significant negative correlation was found between the BCSB memory test delayed recall task scores and the MD values $(p=0.020)$ (Figure 1$)$. The correlated fasciculi were diffusely distributed and represented connections between frontal, temporal and parietal lobes. There was no significant correlation in whole-brain analyses for the RAVLT scores. 


\section{DTI regions of interest analyses}

A significant positive correlation emerged between the BCSB memory test delayed recall task and the FA values in the left hippocampal part of the cingulum $(p=0.033)$ (Figure 2A), and right superior longitudinal fasciculus $(p=0.022)$ (Figure $2 B$ ), and a negative correlation between the BCSB memory test and the MD values in the hippocampal part of the cingulum bilaterally $(\mathrm{p}=0.025)$ (Figure $3 \mathrm{~A})$. As well, a significant negative correlation was found between the RAVLT A1-A5 sum of scores and the MD values in the hippocampal part of the cingulum bilaterally ( $p=0.010$ on the right side and $p=0.022$ on the left side) (Figure 3B). Finally, the RAVLT A7 score had a positive correlation with the FA values in the left hippocampal part of the cingulum ( $p=0.048)$ and negative correlation with the MD values in the right hippocampal part of the cingulum $(\mathrm{p}=0.036)$ (Figure $3 \mathrm{C}$ ). No significant correlation was observed between the RAVLT A1-A5 sum of scores and RAVLT A7 scores and DTI metrics in the superior longitudinal fasciculus. Moreover, no significant correlation emerged between both memory tests and the uncinate fasciculus in ROI analyses.

\section{DISCUSSION}

The study of white matter integrity opens a window to understanding the neural basis of cognition, as connectivity is a major factor that supports cognitive functioning ${ }^{24}$. In the present study, we performed DTI analyses to investigate the neural basis of episodic memory in elderly individuals with low educational attainment. We found significant correlations between the BCSB, a visual-verbal episodic memory test, and the integrity of frontotemporoparietal connection bundles on whole-brain analyses and with the superior longitudinal fasciculus on ROI analyses. Moreover, the BCSB and RAVLT significantly correlated with the hippocampal part of the cingulum integrity bilaterally on ROI analyses.

Episodic memory consists of conscious storage and retrieval of information about previous events, which enables a person to remember the past ${ }^{25}$. Traditionally, since the seminal observations relating severe amnesia due to bilateral hippocampectomy ${ }^{26}$, its function has been attributed to the structure and function of the hippocampus and medial temporal lobe structures. However, research on the

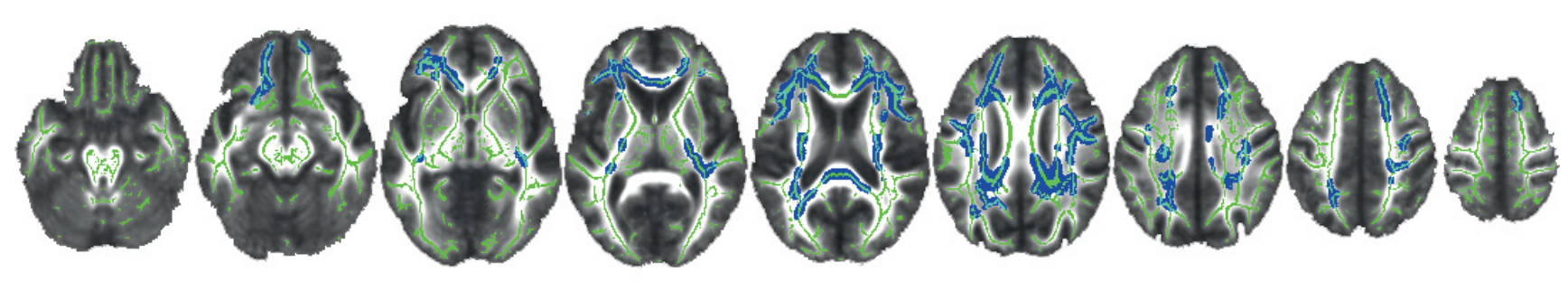

Whole-brain track-based correlation between the mean diffusivity values and the Brief Cognitive Screening Battery memory test delayed recall task score ( $p=$ 0.020 corrected for multiple comparisons across space (Family Wise Error Rate) using threshold-free cluster enhancement). Each panel shows the significant voxel clusters superimposed on the mean diffusivity map in axial slices. Images are displayed in neurological convention (right cerebral hemisphere = right side).

Figure 1. Correlation between white matter integrity and memory in whole-brain analyses.

A

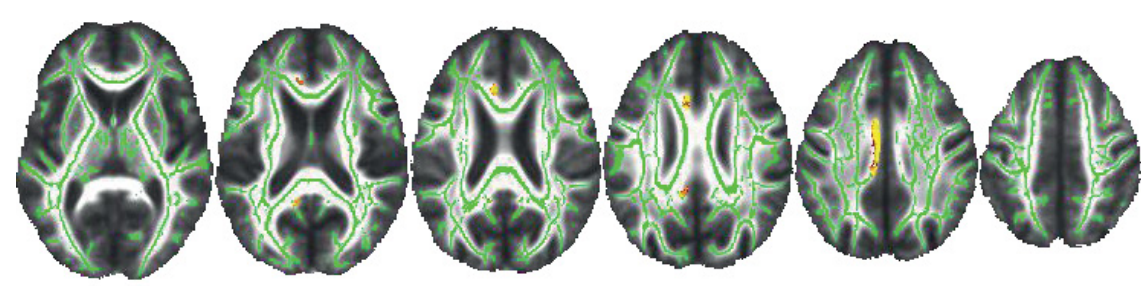

B

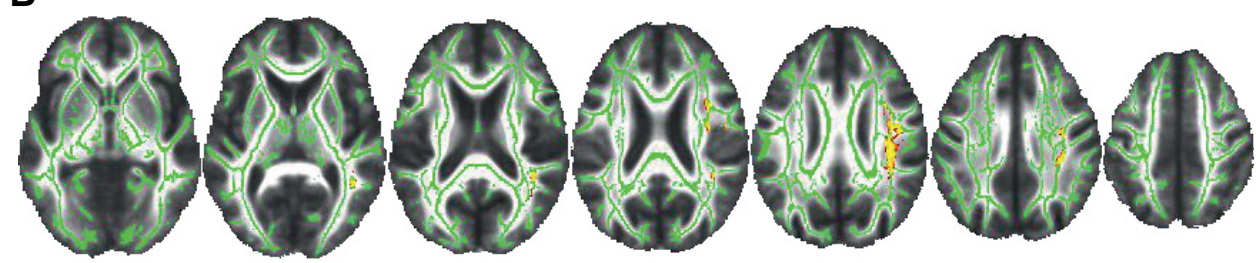

Positive correlation between the Brief Cognitive Screening Battery delayed task score and fraction anisotropy values in the left cingulum ( $p=0.033$ ) (A), and right superior longitudinal fasciculus ( $p=0.022$ ) (B). All analyses were corrected for multiple comparisons across space (Family Wise Error Rate) using thresholdfree cluster enhancement. Each panel shows the significant voxel clusters superimposed on the mean fractional anisotropy map in axial slices. Images are displayed in neurological convention (right cerebral hemisphere = right side).

Figure 2. Correlation between fractional anisotropy and memory in region of interest analyses. 

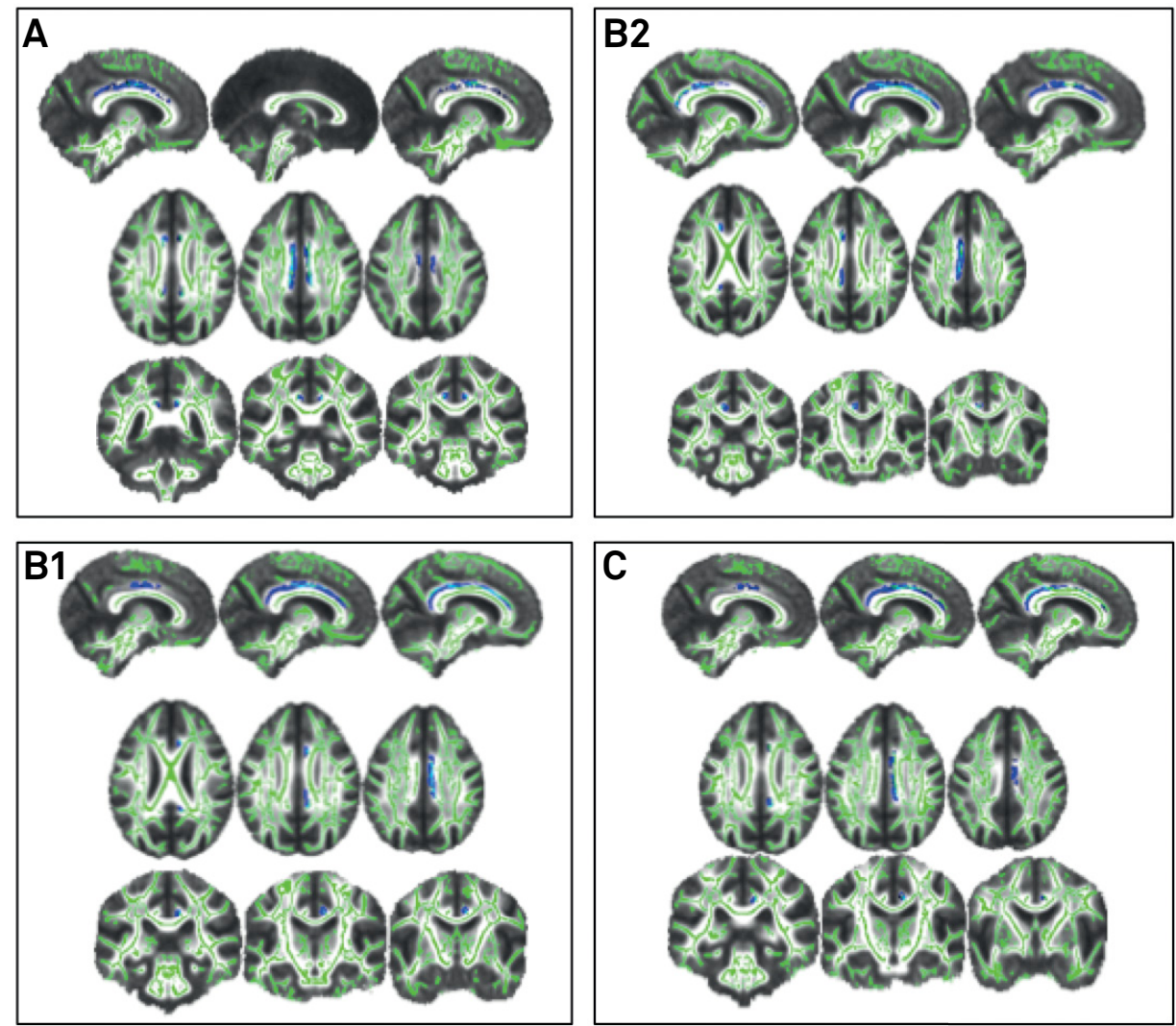

Negative correlation between the Brief Cognitive Screening Battery delayed recall task score and the mean diffusivity values in the cingulum bilaterally $(p=0.025)(A)$. Negative correlations between the Rey Auditory Learning Verbal Test (RAVLT) A1-A5 sum of scores and the mean diffusivity values in the right $(p=0.010)(B 1)$ and left cingulum ( $p=0.022)$ (B2). Negative correlation between the RAVLT A7 score and the mean diffusivity values in the right cingulum $(p=0.036)(C)$. All analyses were corrected for multiple comparisons across space (Family Wise Error Rate) using threshold-free cluster enhancement. Each panel shows the significant voxel clusters superimposed on the mean fractional anisotropy map in axial slices. Images are displayed in neurological convention (right cerebral hemisphere $=$ right side).

Figure 3. Correlation between mean diffusivity and memory in region of interest analyses.

neural basis of memory performance demonstrated that other structures besides the Papez circuit are implicated in memory performance such as the parietal regions, precuneus, posterior cingulate and retrosplenial cortex ${ }^{27}$. Apart from cortical involvement, white matter structures also seem to be critical for memory functioning, as lesions in frontoparietal and frontotemporal fasciculi, including the hippocampal part of the cingulum ${ }^{6}$ and parahippocampal gyrus $^{28}$, may damage the connections between the prefrontal cortex and posterior regions, leading to memory impairment ${ }^{5,29}$. The present study suggests a possible correlation between a visual-verbal episodic memory test with the integrity of white matter bundles in the brain, especially in the temporal regions and their connections with frontotemporal structures, according to the results from the voxelwise analysis. Goldstein et al. showed a similar finding, correlating a visual memory test with white matter integrity in temporal regions in a highly-educated sample ${ }^{30}$. Furthermore, both the visual-verbal and the verbal memory correlated with the integrity of the hippocampal part of the cingulum in the ROI analyses. This tract includes fibers that link the hippocampal formation with the cingulate cortex, both parts of the default mode network. Connections between those areas have been demonstrated to be important for mnemonic processing ${ }^{23}$ and episodic memory performance ${ }^{4,6}$. The present study findings suggest the hippocampal part of the cingulum might also play a role in memory performance in low-educated individuals. In contrast, the right superior longitudinal fasciculus seems to be more relevant in the visual-verbal memory processing, because, in ROI analysis, we only found a significant correlation between the BCSB and the right superior longitudinal fasciculus integrity. Possibly the fact that the superior longitudinal fasciculus has been associated with visual processing $^{23}$, and the strong visual component of the BCSB test, may make them responsible for this finding in only the right hemisphere.

The population-based setting and the very low education attainment of the participants allowed the exploration of the relationships between microstructural white matter integrity and episodic memory performance in this context, which is the reality in developing countries. However, the present study has important limitations. We did not control our analyses for gender and white matter lesions burden. Considering that our sample consisted mostly of women with moderate levels of white matter lesions assessed by the Fazekas scale, 
our findings may apply mainly to individuals with those characteristics. We were unable to perform DTI assessment on all individuals submitted to MRI, which led to a small final sample size. Although relatively common in population-based studies, the drop off in the sample size remained an important limitation for more assertive conclusions. Moreover, because the performance on the RAVLT is influenced by the educational level, there was a floor effect on its performance in the entire sample, with implication on the negative findings regarding the whole-brain analysis. Although important for memory performance, we could not assess the fornix in our study because it is not part of the automated atlas we used and it is difficult to delineate this structure when using the tract-based spatial statistics approach. Furthermore, the different sensitivities of the FA and MD parameters led to few overlaps between the FA and MD findings, which has been described in previous neuroimaging studies ${ }^{7}$ and did not impact on the interpretation of the results.

One of the main goals of aging research is to understand the causes and the pathophysiology of cognitive decline, especially within the memory domain. Our study suggests that the integrity of white matter bundles that connect frontotemporoparietal regions is important for memory performance in the low-educated elderly, similar to that in the highly-educated elderly. Moreover, we identified possible white matter neural correlates of the BCSB test. Because the correlates were consistent with bundles important for memory processing, we believe that our findings reinforce the role of the BCSB test in the clinical setting as an important tool in the diagnostic workup for Alzheimer's disease in individuals with different educational attainments.
The vast majority of scientific studies are conducted in high-income countries, where the population's characteristics frequently lack similarity with the low- and middle-income countries, especially considering the educational level and the socioeconomic status. Although the white matter neural correlates of memory have been studied before, most studies were conducted in developed countries ${ }^{4,5,6}$. Our results, although preliminary, contribute to the field of understanding memory processing in the low-educated elderly. We acknowledge that further studies in a broader sample are necessary to confirm our findings and the next step will be to identify the influence of progressive educational strata on the episodic memory white matter neural correlates. The present findings may contribute to future studies in dementia prevention, since keeping the white matter integrity in frontotemporoparietal connection bundles may have a role in memory processing in the low-educated elderly. Controlling for cardiovascular risk factors to keep the integrity of brain connections might be an important intervention tool to be tested in future studies, to analyze its specific role in preventing memory decline in the elderly.

\section{Acknowledgments}

The authors thank the Pietà Study Group and the D'Or Institute for Research and Education for data collection and analyses. We are also very grateful for the elderly participants of the Pietà study who dedicated their time and energy to our research. We specially thank Luciana Costa Silva for the analysis of the Fazekas score in all images.

\section{References}

1. Dubois B, Feldman HH, Jacova C, Cummings JL, Dekosky ST, Barberger-Gateau P et al. Revising the definition of Alzheimer's disease: a new lexicon. Lancet Neurol. 2010;9(11):1118-27. https://doi.org/10.1016/S1474-4422(10)70223-4

2. Nitrini R, Bottino CM, Albala C, Custodio Capuñay NS, Ketzoian C, Llibre Rodriguez JJ et al. Prevalence of dementia in Latin America: a collaborative study of population-based cohorts. Int Psychogeriatr. 2009;21(4):622-30. https://doi.org/10.1017/S1041610209009430

3. Zola-Morgan S, Squire LR. Neuroanatomy of memory. Annu Rev Neurosci. 1993;16(1):547-63. https://doi.org/10.1146/annurev.ne.16.030193.002555

4. Kantarci K, Senjem ML, Avula R, Zhang B, Samikoglu AR, Weigand SD et al. Diffusion tensor imaging and cognitive function in older adults with no dementia. Neurology. 2011;77(1):26-34. https://doi.org/10.1212/WNL.0b013e31822313dc

5. Lockhart SN, Mayda AB, Roach AE, Fletcher E, Carmichael O, Maillard P et al. Episodic memory function is associated with multiple measures of white matter integrity in cognitive aging. Front Hum Neurosci. 2012;16(6):56. https://doi.org/10.3389/fnhum.2012.00056

6. Irish M, Hornberger M, Wahsh SE, et al. Grey and White matter correlates of recent and remote autobiographical memory retrieval: insights from the dementias. PLoS ONE. 2014;9(11):e113081. https://doi.org/10.1371/journal.pone.0113081
7. Metzler-Baddeley C, Jones DK, Belaroussi B, Aggleton JP, O'Sullivan MJ. Frontotemporal connections in episodic memory and aging: a diffusion MRI tractography study.J Neurosci. 2011;31(37):13236-45. https://doi.org/10.1523/JNEUROSCI.2317-11.2011

8. Ciccarelli O, Werring DJ, Wheeler-Kingshott CA, Barker GJ, Parker GJ, Thompson AJ et al. Investigation of MS normal-appearing brain using diffusion tensor MRI with clinical correlations. Neurology. 2001;56(7):926-33. https://doi.org/10.1212/WNL.56.7.926

9. Beaulieu C. The basis of anisotropic water diffusion in the nervous system: a technical review. NMR Biomed. 2002;15(7-8):435-55. https://doi.org/10.1002/nbm.782

10. Lavdas I, Miquel ME, McRobbie DW, Aboagye EO. Comparison between diffusion-weighted MRI (DW-MRI) at 1.5 and 3 tesla: a phantom study. J Magn Reson Imaging. 2014;40(3):682-90. https://doi.org/10.1002/jmri.24397

11. Smith SM, Jenkinson M, Johansen-Berg H, Rueckert D, Nichols TE, Mackay CE et al. Tract-based spatial statistics: voxelwise analysis of multi-subject diffusion data. Neuroimage. 2006;31(4):1487-505. https://doi.org/10.1016/j.neuroimage.2006.02.024

12. Caramelli P, Barbosa MT, Sakurai E, Dos Santos EL, Beato RG, Machado JC et al. The Pietà study: epidemiological investigation on successful brain aging in Caeté (MG), Brazil. Methods and baseline cohort characteristics. Arq Neuropsiquiatr. 2011;69(4):579-84. https://doi.org/10.1590/S0004-282X2011000500002 
13. Caracciolo B, Palmer K, Monastero R, Winblad B, Bäckman L, Fratiglioni L. Occurrence of cognitive impairment and dementia in the community: a 9-year-long prospective study. Neurology. 2008;70(19 Pt 2):1778-85. https://doi.org/10.1212/01.wnl.0000288180.21984.cb

14. Brucki SM, Nitrini R, Caramelli P, Bertolucci PH, Okamoto IH. [Suggestions for utilization of the mini-mental state examination in Brazil]. Arq Neuropsiquiatr. 2003;61(3B):777-81. Portuguese. https://doi.org/10.1590/S0004-282X2003000500014

15. Nitrini R, Caramelli P, Herrera Júnior E, Porto CS, Charchat-Fichman H, Carthery MT et al. Performance of illiterate and literate nondemented elderly subjects in two tests of long-term memory. J Int Neuropsychol Soc. 2004;10(4):634-8. https://doi.org/10.1017/S1355617704104062

16. Malloy-Diniz LF, Lasmar VA, Gazinelli LS, Fuentes D, Salgado JV. The Rey Auditory-Verbal Learning Test: applicability for the Brazilian elderly population. Rev Bras Psiquiatr. 2007;29(4):324-9. https://doi.org/10.1590/S1516-44462006005000053

17. Wahlund LO, Barkhof F, Fazekas F, Bronge L, Augustin M, Sjögren $M$ et al. A new rating scale for age-related white matter changes applicable to MRI and CT. Stroke. 2001;32(6):1318-22. https://doi.org/10.1161/01.STR.32.6.1318

18. Woods RP, Grafton ST, Holmes CJ, Cherry SR, Mazziotta JC. Automated image registration: I. General methods and intrasubject, intramodality validation. J Comput Assist Tomogr. 1998;22(1):139-52. https://doi.org/10.1097/00004728-199801000-00027

19. Jiang H, Zijl PC, Kim J, Pearlson GD, Mori S. DtiStudio: resource program for diffusion tensor computation and fiber bundle tracking. Comput Methods Programs Biomed. 2006;81(2):106-16. https://doi.org/10.1016/j.cmpb.2005.08.004

20. Pajevic S, Pierpaoli C. Color schemes to represent the orientation of anisotropic tissues from diffusion tensor data: application to white matter fiber tract mapping in the human brain. Magn Reson Med. 1999;42(3):526-40. https://doi.org/10.1002/(SICI)15222594(199909)42:3<526::AID-MRM15>3.0.CO;2-J
21. Smith SM, Jenkinson M, Woolrich MW, Beckmann CF, Behrens TE, Johansen-Berg $\mathrm{H}$ et al. Advances in functional and structural MR image analysis and implementation as FSL. Neurolmage. 2004;23(Suppl 1):S208-19. https://doi.org/10.1016/j.neuroimage.2004.07.051

22. Hua K, Zhang J, Wakana S, Jiang H, Li X, Reich DS et al. Tract probability maps in stereotaxic spaces: analyses of white matter anatomy and tract-specific quantification. NeuroimageNeuroimage. 2008;39(1):336-47. https://doi.org/10.1016/j.neuroimage.2007.07.053

23. Catani M, Schotten MT. A diffusion tensor imaging tractography atlas for virtual in vivo dissections. Cortex. 2008;44(8):1105-32. https://doi.org/10.1016/j.cortex.2008.05.004

24. Mesulam M. Imaging connectivity in the human cerebral cortex: the next frontier? Annals of Neurology. 2005;57(1):5-7. https://doi.org/10.1002/ana.20368

25. Tulving E. Episodic memory: from mind to brain. Annu Rev Psychol. 2002;53(1):1-25.https://doi.org/10.1146/annurev.psych.53.100901.135114

26. Scoville WB, Milner B. Loss of recent memory after bilateral hippocampal lesions.J Neurol Neurosurg Psychiatry. 1957;20(1):11-21. https://doi.org/10.1136/jnnp.20.1.11

27. Cabeza R, Ciaramelli E, Olson IR, Moscovitch M. Parietal cortex and episodic memory: an attentional account. Nat Rev Neurosci. 2008;9(8):613-25. https://doi.org/10.1038/nrn2459

28. Zhuang L, Sachdev PS, Trollor JN, Kochan NA, Reppermund S, Brodaty $\mathrm{H}$ et al. Microstructural white matter changes in cognitively normal individuals at risk of amnestic $\mathrm{MCl}$. Neurology. 2012;79(8):748-54. https://doi.org/10.1212/WNL.0b013e3182661f4d

29. Lee DY, Fletcher E, Martinez O, Ortega M, Zozulya N, Kim J et al. Regional pattern of white matter microstructural changes in normal aging, $\mathrm{MCl}$, and AD. Neurology. 2009;73(21):1722-8. https://doi.org/10.1212/WNL.0b013e3181c33afb

30. Goldstein FC, Mao H, Wang L, Ni C, Lah JJ, Levey Al. White matter integrity and episodic memory performance in mild cognitive impairment: a diffusion tensor imaging study. Brain Imaging Behav. 2009;3(2):132-41. https://doi.org/10.1007/s11682-008-9055-y 